SCIENTIFIC REPORT

\title{
T-bet expression is upregulated in active Behçet's disease
}

\author{
B Li, P Yang, H Zhou, Z Zhang, C Xie, X Lin, X Huang, A Kijlstra
}

Br J Ophthalmol 2003;87:1264-1267

Aim: To investigate T-bet mRNA and protein expression on peripheral blood mononuclear cells (PBMC) in patients with Behçet's disease with active uveitis.

Methods: Blood samples were taken from 24 patients with Behçet's disease who had active uveitis and 16 healthy individuals. PBMC were subjected to analysis of T-bet mRNA and protein expression using semiquatitative reverse transcriptase-polymerase chain reaction (RT-PCR) and western blot, respectively. The products from PCR were sequenced. In order to determine the influence of activation on T-bet expression, the phytohaemagglutinin (PHA) stimulated PBMC from each sample were also evaluated for expression of T-bet mRNA and protein.

Results: A significantly increased T-bet mRNA accumulation was detected in the samples from patients with active Behçet's disease compared with that in controls. A $62 \mathrm{kDa}$ band was detectable in patients with active Behçet's disease, but not in controls. No difference was found between patients with Behçet's disease who had active uveitis and normal controls concerning the expression of either T-bet mRNA or its protein after stimulation with PHA for 72 hours.

Conclusion: Behçet's disease is associated with an upregulation of T-bet expression, which supports a role for the Th1 subset of $T$ cells in the pathogenesis of this disease.

is is well known that the balance between Thl and Th2 cells is essential for the immune homeostasis within the body. Overproduction of Thl cytokines has been implicated in delayed type hypersensitivity reactions and autoimmune diseases. $^{12}$ Numerous studies have been performed to investigate the factors involved in the regulation of Thl cells. T-bet, also known as T-box expression in T cells, is a newly identified Thl specific T-box transcription factor selectively expressed in Thl cells. It is able to target chromatin remodelling of the IFN- $\gamma$ gene in Thl cells and has the unique ability to redirect fully polarised Th2 cells into Th1 cells, as evidenced by simultaneous induction of IFN- $\gamma$ and repression of IL-4 and IL-5.-6

Behçet's disease is a chronic systemic inflammatory disease with unknown aetiology. A number of clinical and laboratory findings suggest a strongly polarised Thl immune response in Behçet's disease. ${ }^{7-12}$ It is not yet clear whether the T-bet protein is involved in the proposed Thl mediated pathogenesis of Behçet's disease at transcriptional level. This study was therefore designed to investigate the expression of T-bet in Behçet's disease using reverse transcriptase-polymerase chain reaction (RT-PCR) and western blot.

\section{PATIENTS AND METHODS}

\section{Patients}

Twenty four patients with Behçet's disease (11 men and 13 women) who had active uveitis were included in this study. The average age of the patients was 36.5 years. The diagnosis of Behçet's disease was based on the criteria designed by the International Study Group for Behçet's disease. ${ }^{13}$ All patients showed a recurrent uveitis and an active intraocular inflammation was noted when sampling was done before visiting our ophthalmic centre. Sixteen healthy individuals (seven men and nine women) served as controls with an average age of 35.4 years. The common ocular findings in these patients with Behçet's disease were non-granulomatous anterior uveitis $(80 \%)$, retinal vasculitis $(95.8 \%)$, and retinitis $(100 \%)$. The common extraocular manifestations were recurrent aphthous stomatitis $(100 \%)$, multiform skin lesions $(91.7 \%)$, recurrent genital ulcer $(54 \%)$, and arthritis $(50 \%)$. All patients had been intermittently treated with systemic steroid, but no immunosuppressive agents were used before collection of these blood samples. All participants were informed about the study and agreed to participate and allowed additional blood sampling for research purposes.

\section{PBMC isolation and culture}

Heparinised blood samples $(8 \mathrm{ml})$ were obtained from patients and healthy individuals and isolation of peripheral blood mononuclear cells (PBMC) was performed by density gradient centrifugation. The PBMC obtained from each sample was divided into two aliquots: one directly subjected to the analysis for T-bet at both mRNA and protein levels and the other for analysis of T-bet after activation of these PBMC with PHA (Sigma, MO, USA) at a concentration of $5 \mu \mathrm{g} / \mathrm{ml}$. For this purpose, the PBMC were cultured with PHA for 72 hours. The cells were collected after the culture and used for T-bet analysis using the following procedure.

\section{RNA preparation and RT-PCR}

Total RNA was extracted from PBMC with or without phytohaemagglutinin (PHA) stimulation by using the Trizol reagent (Gibco Life Technologies, CA, USA) according to the manufacturer's instruction. The obtained samples were quantified by absorbance at $260 \mathrm{~nm}$. Integrity of RNA was checked by electrophoresis on a $1.2 \%$ agarose gel. PBMC cDNA was synthesised and amplified in the ThermoScript RT-PCR System (Gibco Life Technologies, CA, USA) under the conditions stated in the manufacturer's protocol. After PCR reaction conditions were optimised, the PCR reactions were performed in a total volume of $50 \mu \mathrm{l}$ in presence of $2 \mathrm{U}$ of Taq DNA polymerase, $200 \mu \mathrm{mol} / \mathrm{l}$ dNTPs, and $0.5 \mu \mathrm{mol} / \mathrm{l} 5^{\prime}$ and $3^{\prime}$ primers. Reaction was incubated in a GeneAmpPCR system 9700 (PE Biosystems, CA, USA). The PCR procedures included denaturation for 1 minute at $94^{\circ} \mathrm{C}$, annealing for 1 minute at $55^{\circ} \mathrm{C}$, and extension for 1 minute 15 seconds at $72^{\circ} \mathrm{C}$. PCR primers used were as follows: T-bet, sense: 5'-GAGGGTCGCGCTCAACAAC3'; antisense: 5'-GGATGCTGGTGTCAACA GATG-3'; $\beta$ actin, sense: 5'GCCATCCTGCGTCTG-3'; antisense: 5'GGGGCATCGGAACCGCT-3'. To exclude the amplification of genomic DNA contaminating the samples, experiments were also performed using RNA as substrate for PCR assay. Densitometry analysed the bands on the gel after agarose gel electrophoreses. The amplified products were purified using 
QIAquick Gel Extraction kit (Qiagen Company, Hilden, Germany) according to the manufacturer's protocols. T-bet PCR products were sequenced on the applied Biosystems Model 377 DNA Sequencing System.

\section{Protein extraction and western blot analysis}

Total proteins were extracted from both freshly obtained PBMC and those stimulated with PHA by using the lysis buffer (62.5 mM TRIS-HCl pH 6.8, 2\% SDS, 10\% glycerol, $50 \mathrm{mM}$ DTT, $2 \mathrm{mM}$ PMSF, $10 \mu \mathrm{g} / \mathrm{ml}$ aprotinin). The supernatant was collected, centrifuged at $4000 \mathrm{~g}$ for 40 minutes at $4{ }^{\circ} \mathrm{C}$ and stored at $-70^{\circ} \mathrm{C}$ until assay. For detection of T-bet, $20 \mu \mathrm{g}$ of total protein lysate was separated on a $12 \%$ SDSpolyacrylamide gel and electrophoretically and transferred onto PVDF membrane (Boehringer Mannheim, Mannheim, Germany) for 12 hours at $4^{\circ} \mathrm{C}$. T-bet protein was detected after incubation with an anti-T-bet (1:500 final dilution) (Santa Cruz Biotechnology, CA, USA) and subsequent incubation with HRP peroxidase conjugated rabbit antigoat IgG mAb ( 1:2000 final dilution) (Santa Cruz Biotechnology, CA, USA). The reaction was detected with a Chemiluminescence detection kit (Cell Signalling Technology, Beverly, USA).

\section{Statistical analysis}

Statistical analysis was performed using the $t$ test for two independent samples, whereby $\mathrm{p}<0.05$ was considered significant.

\section{RESULTS}

\section{Expression of T-bet mRNA in patients with Behçet's} disease and controls

The obtained PCR products were sequenced and showed a 99.6\% homology. Using the optimised conditions, an increased level of T-bet mRNA transcripts was observed in all of the tested patients (Fig 1). The average ratio of T-bet to $\beta$ actin mRNA levels was 0.86 in patients whereas that in controls was 0.3 . There was no significant correlation of this ratio with the clinical severity of the uveitis. The difference in the ratio of T-bet to $\beta$ actin mRNA levels between patients and controls was statistically significant $(p<0.001)$.

In order to evaluate the influence of activation of PBMC on T-bet mRNA, its expression was also investigated after stimulating PBMC with PHA both in patients and controls. The expression of T-bet mRNA was markedly increased in the controls after stimulation. The ratio of $\mathrm{OD}$ value was significantly higher after stimulation (average 0.8 ) than that before stimulation (average 0.3$)(\mathrm{p}<0.001)$. Unexpectedly, the expression of T-bet mRNA in PBMC after PHA stimulation in patients (average 0.87) was not increased compared with that before stimulation (average 0.86). There was no difference between patients and controls concerning the ratio of T-bet to $\beta$ actin mRNA levels after stimulation with PHA (Fig 2).
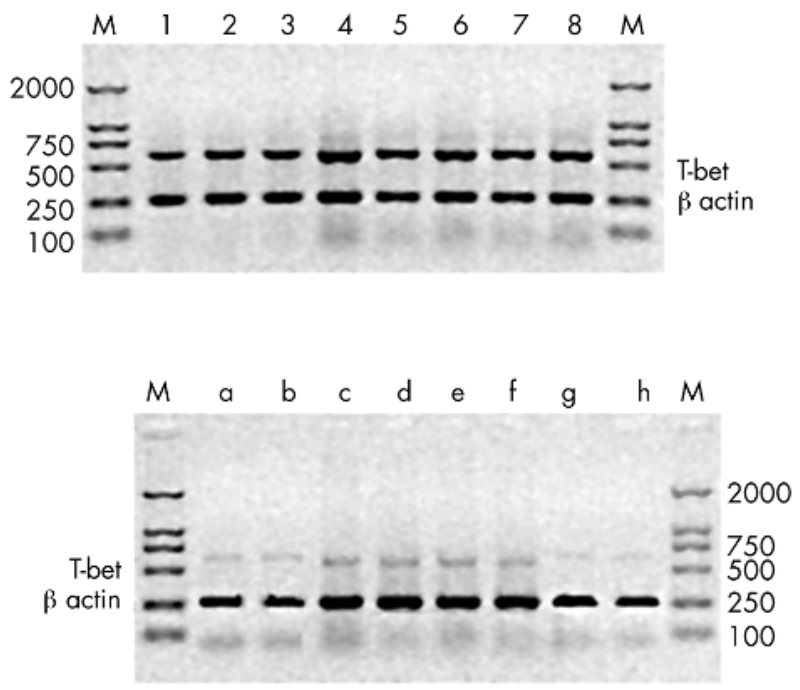

Figure 1 RT-PCR analysis T-bet and $\beta$ actin in PBMC from eight patients with active Behcet's disease (lanes 1-8) and eight normal controls lane $\mathrm{a}-\mathrm{h})$. One representative experiment is presented out of the 12 patients with active Behçet's disease and 10 controls studied in total. The other patients showed a similar pattern of response. Upregulation of T-bet mRNA expression was detected in active Behçet's disease.

\section{Expression of T-bet protein in patients and controls}

A protein with a molecular size of approximately $62 \mathrm{kDa}$ was detected in the PBMC from all patients with Behçet's disease. However, this protein was not detectable in the controls (Fig 3). After incubation of the PBMC with PHA, all of the samples, no matter whether they were obtained from patients or from controls, showed a protein with a molecular weight of $62 \mathrm{kDa}$. Furthermore, qualitative analysis indicated that the expression of T-bet protein was similar between patients and controls (Fig 4).

\section{DISCUSSION}

In this study, a markedly increased expression of T-bet at both the mRNA and protein level was noted in PBMC from patients with Behçet's disease with active uveitis compared with that in controls. It has been suggested that T-bet expression is increased in activated $\mathrm{T}$ cells. Therefore, the expression of T-bet both at the mRNA level and protein level was expected to be upregulated after activation of the T cells from the controls. The experiment of stimulating PBMC from these controls with PHA and the analysis of T-bet mRNA and protein indeed revealed an increase in T-bet expression, confirming the validity of the techniques used in the study and de facto upregulated T-bet expression in patients with Behçet's disease who had active intraocular inflammation.

The study on the expression of T-bet has a particular implication in view of its regulatory role in the polarisation of Thl cells. Numerically and functionally increased Thl cells

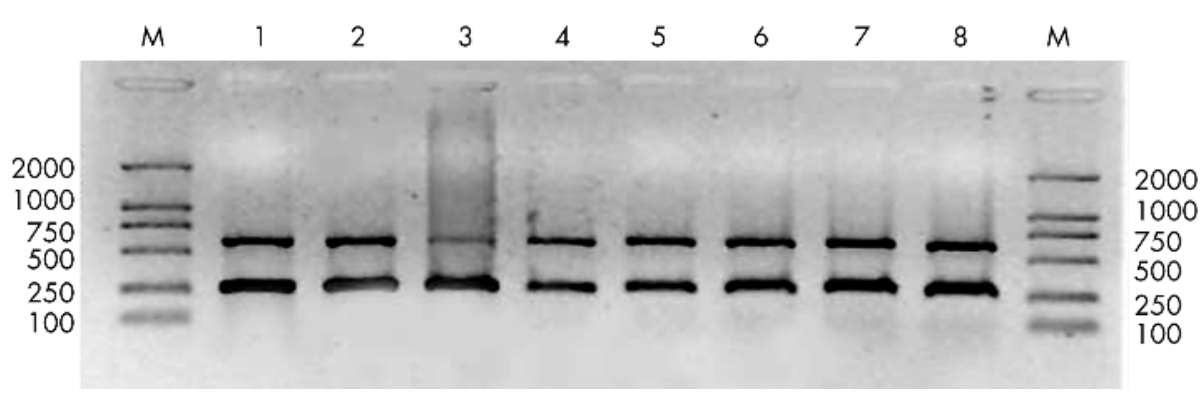

Figure 2 RT-PCR analysis of T-bet and $\beta$ actin in PHA stimulated PBMC from four normal controls (lanes 1-4) and four patients with active Behçet's disease (lanes 5-8). The procedures used in this experiment were the same as listed in Figure 1. 


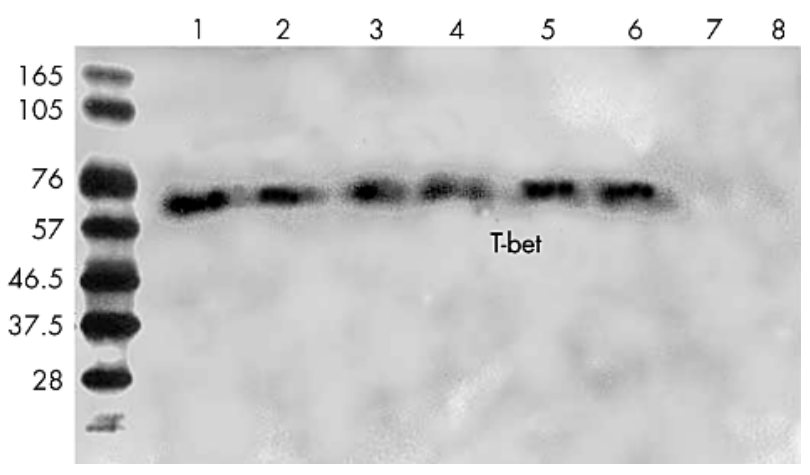

Figure 3 Western blotting analysis of T-bet protein expression in PBMC from patients with active Behçet's disease and normal controls. A $62 \mathrm{kDa}$ protein is detected in all samples from patients with Behçet's disease (lanes 1-6), but not in normal controls (lanes 7, 8). One representative experiment of two independent experiments is shown.

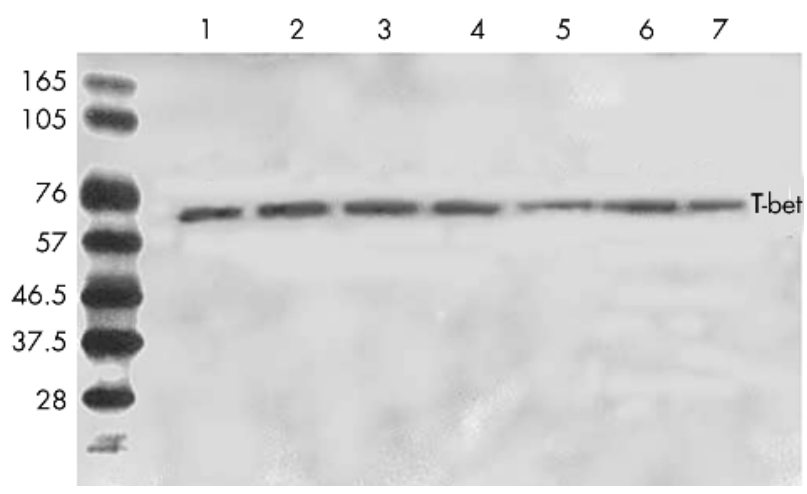

Figure 4 T-bet expression in PBMC from patients with Behçet's disease and normal controls. After cells were cultured with PHA for 72 hours, a $62 \mathrm{kDa}$ protein was detected in all samples tested either from patients with Behçet's disease (lanes 1-4) or from normal controls (lanes 5-7). One representative experiment of two independent experiments is shown.

are implicated in the development of a variety of autoimmune diseases including Behçet's disease. ${ }^{12}$ Recent studies have revealed that the polarisation of $\mathrm{T}$ lymphocytes into differentiated effector subsets is closely controlled by a variety of transcription factors. ${ }^{14}{ }^{15}$ It has been shown that Statl, Stat4, and T-bet are involved in the regulation and polarisation of Thl cells at the transcriptional level. ${ }^{16}{ }^{17}$ It has been established that Stat proteins may not be critical in regulating the transcription of the IFN- $\gamma$ gene. ${ }^{18}{ }^{19}$ T-bet has been shown to be selectively expressed on Thl cells. It has a central role in the development of Thl cells through activating Thl genetic programmes and repressing cytokine synthesis of Th2 cells. ${ }^{3}{ }^{20}$ It is apparent that T-bet is a master switch for Thl cell development. Therefore, the study on Tbet may provide an insight into the mechanisms of various autoimmune diseases including Behçet's disease at the transcriptional level.

The increased mRNA and protein expression of T-bet in patients with active Behçet's disease, as shown in this study, is in accordance with previously reported results. Studies have revealed that IFN- $\gamma$ is critical in regulating the IL- 4 , IL10 , and IL-2 cytokine network pathway in Behçet's disease; high serum levels of IL-2 and IFN- $\gamma$ have also been observed in these patients. ${ }^{1920}$ The results presented here, together with those stated above, clearly show that activation of Thl cells is an important feature in patients with Behçet's disease who had active uveitis and may be critical in the pathogenesis of this disease.

Studies on T-bet in coeliac disease (other Thl mediated autoimmune diseases) and asthma (Th2 mediated disease) have revealed results similar to those presented here. Salvati et al have found that T-bet expression was increased in the inflamed mucosa of patients with coeliac disease. ${ }^{21}$ Contrary to the results stated above, relatively fewer T-bet expressing $\mathrm{CD}^{+} \mathrm{T}$ cells were found in the airway of the patients with asthma compared with controls. ${ }^{22}{ }^{23}$ These results are in accordance with the concept that upregulation of T-bet is instrumental in the development of autoimmune diseases, and its downregulation is involved in allergic disease.

It is interesting to note that no difference could be observed with regard to the expression of T-bet mRNA and protein in our Behçet's disease patients before and after stimulation with PHA, although a significant difference was readily detected in the controls. The upregulation of T-bet in these patients was expected to be similar to that seen in the controls. This result may suggest that a large number of activated Thl cells are already present in PBMC of Behçet's disease patients with active intraocular inflammation.

Our study has some limitations. We do not know the expression of T-bet in inactive Behçet's disease. In addition, it would be interesting to investigate whether the Thl activation is reflected by the intraocular or serum cytokine profiles (for example, IFN- $\gamma$ and IL-4). Addressing these problems will greatly enhance our understanding of the pathogenesis of uveitis and may substantially contribute to the study on strategy of the prevention and treatment of uveitis.

\section{ACKNOWLEDGEMENTS}

We are grateful to Dr Zaiyu Peng for her technical assistance. This work was supported by the National Outstanding Youth Foundation (39925034), National Nature Science Foundation (30271387), Guangdong province Nature Science Foundation (021819).

\section{Authors' affiliations}

B Li, P Yang, H Zhou, Z Zhang, C Xie, X Huang, Zhongshan Ophthalmic Center, Sun Yat-sen University, Guangzhou, P R China

$X$ Lin, Immunology Department, Sun Yat-sen University, Guangzhou, P R China

A Kijlstra, Department of Ophthalmology, Eye Research Institute Maastricht, Maastricht, Netherlands

Correspondence to: Professor P Yang, Zhongshan Ophthalmic Center, 54 Xianlie Road, Guangzhou 510060, P R China; peizengyang@hotmail.com or ypzn@gzsums.edu.cn

Accepted for publication 2 July 2003

\section{REFERENCES}

1 O'Garra A. Cytokines induce the development of functionally heterogeneous T helper cell subsets. Immunity 1998;8:275-83.

2 Romagnani S. Lymphokine production by human T cells disease states. Annu Rev Immunol 1994; 12:227-93.

3 Szabo SJ, Kim ST, Costa GL, et al. A novel transcription factor, T-bet, direct Th1 lineage commitment. Cell 2000;100:655-69.

4 Papaioannou VE. T-box genes in development: from hydra to humans. Int Rev Cytol 2001;207:1-70.

5 Grogan JL, Mohrs M, Harmon B. Early transcription and silencing of cytokine genes underlie polarization of T helper cell subsets. Immunity $2001 ; 14: 205-15$

6 Mullen AC, High FA, Hutchins AS. Role of T-bet in commitment of $\mathrm{TH} 1$ cells before IL-12-dependent selection. Science 2001;292:1907-10.

7 Hirohata S, Hashimoto T. Abnormal T cell responses to bacterial superantigens in Behçet's disease. Clin Exp Immunol 1998;112:317-24.

8 Yamashita N, Kaneoka H, Kaneko S, et al. Role of $\lambda \delta$ T lymphocytes in the development of Behçet's disease. Clin Exp Immunol 1997; 107:241-7.

9 Sayinalp N, Ozcebe OI, Ozdemir O, et al. Cytokines in Behçet's disease. J Rheumatol 1996;23:321-2. 
10 Raziuddin S, al-Dalaan A, Bahabri S, et al. Divergent cytokine production profile in Behçet's disease. Altered Th1/Th2 cell cytokine pattern. J Rheumatol 1998;25:329-33.

11 Sugikai N, Nakazawa M, Nakamura S, et al. Increased frequencies of interleukin-2 and interferon-gamma producing $T$ cells in patients with active Behçet's disease. Invest Ophthalmol Vis Sci 1998;39:996-1004.

12 Mochizuki M. Immunotherapy for Behçet's disease. Int Rev Immunol 1997:14:49-66.

13 International Study Group for Behçet's Disease. Criteria for diagnosis of Behçet's disease. Lancet 1990;335:1078-80.

14 Rengarajan J, Szabo SJ, Glimcher LH. Transcriptional regulation of Th1/Th2 polarization. Immunol Today 2000;21:479-83.

15 Asnagli H, Merphy KM. Stability and commitment in T helper cell development. Curr Opin Immunol 2001;13:242-7.

16 Carter LL, Murphy KM. Lineage-specific requirement for signal transducer and activator of transcription Stat4 in interferon-a production from CD4+ versus CD8 +T cells. J Exp Med 1999; 189:1355-60.
17 Durbin JE, Hackenmiller R, Simon MC, et al. Targeted disruption of the mouse Statl gene results in compromised innate immunity to viral disease. Cell 1996;84:443-50.

18 O'Garra A. Checkpoints for regulation of development and interferon-gamma production by Th1 cells in TCR-transgenic model. Eur. Cytokine Netw 1998;2:41-2.

19 Emmi L, Brugnolo F, Marchione T. Pathogenesis and therapy of Behçet's disease. Ann Ital Med Int 1997; 12:20-5.

20 Frassanito MA, Dammacco R, Cafforio $P$, et al. Th1 polarization of the immune response in Behcet's disease, a putative pathogenetic role of interleukin-12. Arhritis Rheum 1999;42:1967-74

21 Salvati VM, MacDonald TT, Bajaj-Elliott, et al. Interleukin 18 and associated markers of T helper cell type 1 activity in celiac disease. Gut 2002;50:186-90.

22 Finotto S, Neurath MF, Glickman JN, et al. Development of spontaneous airway changes consistent with the asthma in mice lacking T-bet. Science 2002;295:336-8.

23 Robinson DS, Lloyd CM. Asthma: T-bet a master controller? Curr Biol 2002;12:R332-4.

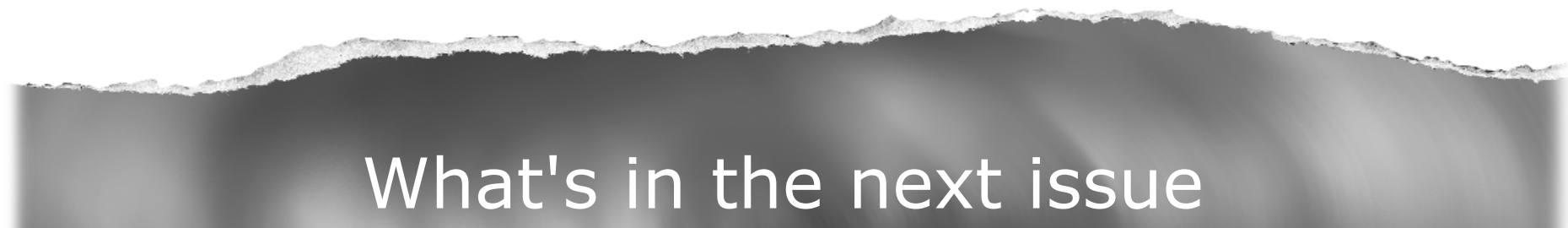

\section{Future content}

See which articles have just been accepted for publication and preview the table of contents for the next issue a month before it is published

\section{www.bjophthalmol.com}

